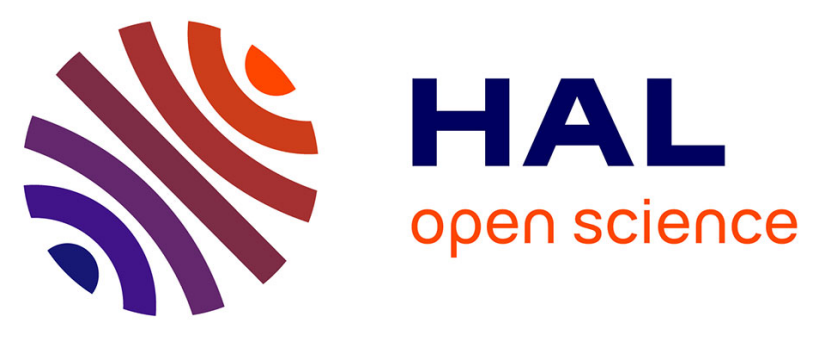

\title{
Respective pharmacological features of neuropathic-like pain evoked by intrathecal BDNF versus sciatic nerve ligation in rats
}

Saïd M'dahoma, Sandrine Barthélemy, Claire Tromilin, Tiffany Jeanson, Florent Viguier, Benoit Michot, Sophie Pezet, Michel Hamon, Sylvie Bourgoin

\section{- To cite this version:}

Saïd M'dahoma, Sandrine Barthélemy, Claire Tromilin, Tiffany Jeanson, Florent Viguier, et al.. Respective pharmacological features of neuropathic-like pain evoked by intrathecal BDNF versus sciatic nerve ligation in rats. European Neuropsychopharmacology, 2015, 25 (11), pp.2118-2130. 10.1016/j.euroneuro.2015.07.026 . hal-01289208

\section{HAL Id: hal-01289208 https://hal.sorbonne-universite.fr/hal-01289208}

Submitted on 16 Mar 2016

HAL is a multi-disciplinary open access archive for the deposit and dissemination of scientific research documents, whether they are published or not. The documents may come from teaching and research institutions in France or abroad, or from public or private research centers.
L'archive ouverte pluridisciplinaire HAL, est destinée au dépôt et à la diffusion de documents scientifiques de niveau recherche, publiés ou non, émanant des établissements d'enseignement et de recherche français ou étrangers, des laboratoires publics ou privés. 


\section{Respective pharmacological features of neuropathic-like pain evoked by intrathecal BDNF versus sciatic nerve ligation in rats}

Saïd M'Dahoma ${ }^{a, b}$, Sandrine Barthélemy ${ }^{a, b}$, Claire Tromilin ${ }^{a, b}$, Tiffany Jeanson ${ }^{b, d}$, Florent

Viguier $^{a, b}$, Benoit Michot ${ }^{a, b}$, Sophie Pezet ${ }^{e}$, Michel Hamon ${ }^{a, b, c}$, Sylvie Bourgoin $^{a, b, c, *}$

${ }^{\mathrm{a} C e n t r e ~ d e ~ P s y c h i a t r i e ~ e t ~ N e u r o s c i e n c e s, ~ I N S E R M ~ U M R ~ 894, ~ P a r i s ~ F-75014, ~ F r a n c e ~}$

${ }^{b}$ Université Pierre et Marie Curie - Paris 6, Faculté de Médecine Pierre et Marie Curie, Site Pitié-Salpêtrière, Paris F-75013, France

'Université Paris Descartes, Sorbonne Paris Cité - Paris 5, France

${ }^{\mathrm{d}}$ Theranexus, 91400 Orsay, France

e UMR 8249 CNRS - Brain Plasticity Unit, ESCPI-ParisTech, Paris F-75005, France

*Corresponding author at :

INSERM U894 - Centre de Psychiatrie et Neurosciences

2ter, rue d'Alésia

75014 Paris

France

Tel : 33140788636

Fax : 33145807293

E-mail address: sylvie.bourgoin@upmc.fr (Sylvie Bourgoin)

Short title : BDNF-versus nerve ligation-evoked neuropathic-like pain

Abstract : 250 words

Whole manuscript (including references) : 6389 words

References : 44

Tables : 0

Figures : 9 


\section{ABSTRACT}

Numerous reported data support the idea that Brain Derived Neurotrophic Factor (BDNF) is critically involved in both depression and comorbid pain. The possible direct effect of BDNF on pain mechanisms was assessed here and compared with behavioral/neurobiological features of neuropathic pain caused by chronic constriction injury to the sciatic nerve $(\mathrm{CCl}-$ SN). Sprague-Dawley male rats were either injected intrathecally with BDNF (3.0 ng i.t.) or subjected to unilateral CCI-SN. Their respective responses to anti-hyperalgesic drugs were assessed using the Randall-Selitto test and both immunohistochemical and RT-qPCR approaches were used to investigate molecular/cellular mechanisms underlying hyperalgesia in both models. Long lasting hyperalgesia and allodynia were induced by i.t. BDNF in intact healthy rats like those found after CCI-SN. Acute treatment with the BDNF-TrkB receptor antagonist cyclotraxin B completely prevented i.t. BDNF-induced hyperalgesia and partially reversed this symptom in both BDNF-pretreated and $\mathrm{CCI}-\mathrm{SN}$ lesioned rats. Acute administration of the anticonvulsant pregabalin, the NMDA receptor antagonist ketamine, the opioid analgesics morphine and tapentadol or the antidepressant agomelatine also transiently reversed hyperalgesia in both i.t. BDNF injected- and CCI-SN lesioned-rats. Marked induction of microglia activation markers (OX42, Iba1, P-p38), proinflammatory cytokine IL-6, NMDA receptor subunit NR2B and BDNF was found in spinal cord and/or dorsal root ganglia of CCl-SN rats. A long lasting spinal BDNF overexpression was also observed in BDNF i.t. rats, indicating an autocrine self-induction, with downstream long lasting TrkB-mediated neuropathic-like pain. Accordingly, TrkB blockade appeared as a relevant approach to alleviate not only i.t. BDNF- but also nerve lesion-evoked neuropathic pain.

Key words: BDNF, neuropathic pain, chronic constriction injury, microglia activation, TrkB receptor, cyclotraxin $\mathrm{B}$ 


\section{1 - Introduction}

Comorbidity between depression and chronic neuropathic pain has been repeatedly reported in the relevant literature, suggesting the existence of at least some common underlying mechanisms (Chopra and Arora, 2014). In support with this inference, first line treatment of chronic neuropathic pain is based on effective antidepressant drugs, especially tricyclics and mixed inhibitors of noradrenaline and serotonin reuptake (Finnerup et al., 2015). However, whether antidepressant drugs really act through a facilitation of monoaminergic neurotransmission to reduce neuropathic pain is still a matter of debate. Indeed, these drugs can also affect neuroinflammatory processes, interact directly with voltage-dependent cation channels involved in the transmission of nociceptive signals and block some pain-related receptors, and these actions might also contribute to their antineuropathic pain properties (Vranken, 2012).

Among endogenous molecules involved in both depression and antidepressants' action on the one hand, and chronic pain on the other hand, the neurotrophin Brain Derived Neurotrophic Factor (BDNF) seems to play cardinal roles (Pezet and McMahon, 2006; Autry and Monteggia, 2012). A large consensus has led to the conclusion that depression is associated with BDNF downregulation in brain areas such as the hippocampus and the frontal cortex (Cai et al., 2015), and it has been recently proposed that depression-like behavior caused by some pro-inflammatory cytokines might be underlain by their capacity to downregulate hippocampal BDNF (Calabrese et al., 2014). Conversely, antidepressants, including the atypical antidepressant ketamine, have been shown to enhance BDNF production, or even transactivate the BDNF-TrkB (tropomyosin receptor kinase B) receptor, thereby counteracting depression-associated BDNF-TrkB downregulation (Lindholm and Castrén, 2014). That antidepressants could act through supraspinal BDNF-TrkB activation is supported by data showing that direct intracerebral administration of BDNF itself exerts antidepressant-like effects in validated rodent models of depression (Shirayama et al., 2002).

However, it would be irrelevant to infer that an upregulation of BDNF always contributes to an antidepressant action because direct injection of BDNF into the ventral tegmental area was found to cause depression-like behavior, whereas BDNF signaling blockade in the nucleus accumbens produced antidepressant-like effects (Berton et al., 2006). 
Regarding pain, the role of BDNF is also a matter of debate because both antinociceptive (Cejas et al., 2000; Lever et al., 2003) and pronociceptive (Groth and Aanonsen, 2002; Constandil et al., 2011, 2012) effects have been reported after direct administration of this neurotrophin intracerebroventricularly or intrathecally (i.t.) in rodents. Furthermore, inflammatory but not neuropathic pain seems to implicate BDNF (Zhao et al., 2006), which may suggest that the anti-neuropathic pain effect of antidepressants would not involve this neurotrophin, in line with a recent report showing that the antihyperalgesic effect of amitriptyline was not associated with any change of spinal BDNF levels in CCI-SN rats (Vanelderen et al., 2013).

All these rather heterogeneous data led us to reinvestigate the effects of direct administration of BDNF at spinal level for a thorough comparison with authentic neuropathic pain symptoms caused by unilateral chronic constriction injury to the sciatic nerve (CCl-SN) in rats. In particular, drugs known to be effective to alleviate neuropathic pain, especially antidepressants, anticonvulsants and opioids (Finnerup et al., 2015) were tested in both BDNF-treated and CCl-SN-lesioned rats. In addition, quantitative RT-PCR and immunohistochemistry were used to investigate whether microglial and neuroplasticity markers were affected in BDNF i.t. rats like that previously described in CCI-SN rats (Latrémolière et al., 2008). Finally, whether BDNF-TrkB blockade by cyclotraxin B (Cazorla et al., 2010) could antagonize not only BDNF i.t.- but also CCl-SN-induced allodynia/hyperalgesia was also assessed.

\section{Experimental procedures}

\subsection{Animals}

Adult male Sprague-Dawley rats (175-200 g on arrival from Charles River Breeding Center, 69210 L'Arbresle, France) were housed in a controlled environment $\left(22^{\circ} \pm 1{ }^{\circ} \mathrm{C}, 60 \%\right.$ relative humidity, 12:12 $\mathrm{h}$ light-dark cycle, lights on at 7:00 a.m.) with food and water available ad libitum, under resting conditions (no handling) for at least 1 week before experiments. All experiments were performed in conformity with the Guidelines of the Committee for Research and Ethical Issues of the International Association for the Study of Pain 
(Zimmermann, 1983) and strictly followed the Institutional Guidelines that are in compliance with national and international laws and policies for use of animals in neuroscience research (Council Directive 86/609/EEC of the the European Communities, November 24, 1986; Council Directive 87-848 of the French Ministère de l'Agriculture et de la Forêt, Service vétérinaire de la santé et de la protection animale, October 19, 1987; permissions nb A752128 to S.M., nb 75116 to M.H., nb 006228 to S.B.).

\subsection{Surgery}

\subsubsection{Chronic constriction injury to the sciatic nerve}

Rats were anesthetized with sodium pentobarbital (50 mg/kg, i.p.), and unilateral CCI-SN was made according to the procedure of Bennett and Xie (1988). Briefly, the right common sciatic nerve was exposed at mid-thigh level and freed from adhering tissue allowing the disposition of four ligatures (5.0 silk suture) tied loosely with $1 \mathrm{~mm}$ spacing. Sham rats underwent the same surgery without ligatures. Muscle and skin were then closed in layers with silk suture (4.0) and rats were allowed to recover for one week in their home cage.

\subsubsection{Intrathecal injection}

Rats were slightly anesthetized using isoflurane $(3 \%$ in air) and injected into the subarachnoid space between L5 and L6 vertebrae using a $26 \mathrm{G}$ needle connected to a Hamilton syringe (Mestre et al., 1994). Each rat received $12 \mu \mathrm{L}$ of vehicle $(0.9 \% \mathrm{NaCl})$ or BDNF solution ("BDNF i.t.", Peprotech, 92200 Neuilly, France). The dose of BDNF (3.0 ng/12 $\mu \mathrm{L}$ of saline) was selected from previous studies (Groth and Aanonsen, 2002; Constandil et al., 2011, 2012).

\subsection{Behavioral tests}

All tests were performed by an experienced person blind to treatment groups.

\subsubsection{Paw pressure test}

Mechanical nociceptive thresholds, expressed as grams (g), were measured using an Ugo Basile algesimeter (Bioseb, 92370 Chaville, France) according to Randall and Selitto (1957). Pressure thresholds to trigger paw withdrawal then vocalization (Kayser et al., 2010) were 
determined on the day before nerve injury or intrathecal injection (basal values) and then on day 15 after surgery for $\mathrm{CCl}$-SN rats or on day 10 after i.t. injection for BDNF i.t. rats, when hypersensitivity to mechanical stimulation had fully developed (see Results). Pharmacological treatments started immediately thereafter, and thresholds were determined at regular time intervals (30 or $60 \mathrm{~min}$ ) after drug administration. Only animals showing clear-cut mechanical hypersensitivity (approximately $60 \%$ of CCI-SN rats and $80 \%$ of BDNF i.t. rats), with a reduction of nociceptive thresholds of at least $30 \%$ compared to shamoperated/vehicle i.t. rats, were used for pharmacological studies.

\subsection{2. von Frey filaments test}

Each rat was first habituated for two hours in a quiet room, and mechanical sensitivity was then determined with a graded series of eight von Frey filaments $(4,6,8,10,12,15,26$ and $60 \mathrm{~g}$; Latrémolière et al., 2008) applied to the lateral plantar surface of hindpaw (ipsilateral to CCI-SN, bilaterally in BDNF i.t. rats). The up-down procedure of Chaplan et al. (1994) was used to determine the pressure threshold to trigger hindpaw withdrawal. When no response was observed, the force of the thickest filament $(60 \mathrm{~g})$ was arbitrarily assigned as the "cutoff" value (see Latrémolière et al., 2008).

\subsection{Pharmacological treatments}

Cyclotraxin B (Bio S\&T, Montreal, Canada), pregabalin (Sequoia, Pangbourne, UK), morphine (Pharmacie Centrale des Hôpitaux de Paris, France), tapentadol (Grünenthal, Aachen, Germany), agomelatine (Servier, Suresnes, France), ketamine, duloxetine and amitriptyline (Sigma-Aldrich, Saint-Quentin Fallavier, France), clonazepam (Roche, Basel, Switzerland) were administered using routes and doses previously reported to be active at their respective molecular targets (Cazorla et al., 2010; de Bodinat et al., 2010; Lau et al., 2013; Michot et al., 2013; M'Dahoma et al., 2014). Drugs were injected i.p. in a volume of $1 \mathrm{~mL} / \mathrm{kg}$, except morphine which was injected subcutaneously $(1 \mathrm{~mL} / \mathrm{kg}$, s.c.). Cyclotraxin B, morphine, tapentadol, pregabalin, ketamine and amitriptyline were dissolved in $0.9 \% \mathrm{NaCl}$. Agomelatine and duloxetine were dissolved in $1 \%$ hydroxyethylcellulose (HEC) in water, and clonazepam in ethanol:water (50:50). Control animals received respective vehicles using the same routes of administration. 


\subsection{Immunohistochemistry}

\subsubsection{Stroking stimulation}

Previous studies showed that gentle (non noxious) mechanical stimulation of hindpaw allowed immunocytochemical visualization of neuronal sensitization underlying hyperalgesia/allodynia-like responses in rats (Kayser et al., 2010). This protocol was used here to look for possible neuronal sensitization at spinal level in rats that had been i.t. injected with BDNF 10 days before. Briefly, gentle touch stimulus with a paint brush was applied once every $10 \mathrm{sec}$ for $10 \mathrm{~min}$ to the right hindpaw. This touch stimulus feels like a stroke in human volunteers and does not elicit a flexion reflex in naïve healthy rats. Such stroking stimulation was performed $24 \mathrm{~h}$ before deep anesthesia and perfusion for immunohistochemical procedure (2.5.2.).

\subsubsection{Immunohistochemical procedure}

Fifteen days after $\mathrm{CCl}-\mathrm{SN}$ and 11 days after i.t. BDNF, rats were deeply anesthetized with pentobarbital $(50 \mathrm{mg} / \mathrm{kg}$ i.p.) and perfused intracardially with a heparin (25 IU/ml)-saline solution, followed by $0.12 \mathrm{M}$ phosphate buffered saline (PBS, $\mathrm{pH} 7.4$ ) containing $4 \%$ paraformaldehyde, $0.1 \%$ glutaraldehyde and $0.05 \%$ picric acid, and finally by $20 \%$ sucrose solution. The spinal cord was removed and cryoprotected in $20 \%$ sucrose solution overnight. Coronal floating sections ( $30 \mu \mathrm{m}$ thick) of the lumbar enlargement were collected and then processed in parallel, with the same reagents, under the very same conditions (see Kayser et al., 2010). To label phospho-p38 (P-p38), the activated form of p38 MAP kinase (Jin et al., 2003), sections were incubated with the primary antibody (rabbit anti-P-p38, 1/3,000, Cell Signaling Inc, Danvers, MA, USA) in PBS-T-azide (0.02 M PBS containing 0.3\% Triton X-100 and $0.02 \%$ sodium azide) overnight at room temperature. After rinsing with PBS, the sections were incubated for $1 \mathrm{~h}$ with the secondary antibody (biotinylated goat anti-rabbit, 1/1,000, Vector, Burlingame, CA, USA) in PBS containing 0.3\% Triton X-100, then rinsed again with PBS and finally incubated for $1 \mathrm{~h}$ in the avidin-biotin horseradish-peroxidase solution ( $A B C$ Vectastain kit Elite, Vector). Immunolabeling was revealed with peroxidase substrate kit (SK4100 , Vector), and sections were sequentially treated with 50\%, 70\%, 90\%, 95\% absolute ethanol and xylene, before cover-slipping with Eukitt (Sigma-Aldrich, St Louis, MO, USA). Pp38 immunoreactive cells within the superficial (I-II) and deep (III-V) laminae of the dorsal 
horn were counted in each $30 \mu \mathrm{m}$ thick coronal section every $180 \mu \mathrm{m}$ at L4-L6 levels using the software Mercator (see Kayser et al., 2010).

\subsection{Real time quantitative RT-PCR}

BDNF i.t. rats (24 $\mathrm{h}$ and 10 days after i.t. injection), CCI-SN rats (15 days after surgery) and their respective controls were killed by decapitation. Dorsal root ganglia (DRG, on the right side in $\mathrm{CCl}-\mathrm{SN}$ rats) and the dorsal half of the lumbar cord (ipsilateral dorsal quadrant for $\mathrm{CCl}-$ $\mathrm{SN}$ rats) at L4-L6 were rapidly dissected at $0-4{ }^{\circ} \mathrm{C}$, and immediately frozen in liquid nitrogen to be stored at $-80{ }^{\circ} \mathrm{C}$. Total RNA was extracted using the NucleoSpin RNA II extraction kit (Macherey-Nagel, 67722 Hoerdt, France) and quantified using a NanoDrop. First-stranded cDNA synthesis was carried out using High capacity cDNA reverse transcription kit (Applied Biosystems, Courtaboeuf, France). PCR amplification, in triplicate for each sample, was performed using ABI Prism 7300 (Applied Biosystems), TaqMan ${ }^{\circledR}$ Universal PCR Master Mix No AmpErase ${ }^{\circledR}$ UNG (Applied Biosystems) and Assays-on-Demand Gene Expression probes (Applied Biosystems) for target genes: ATF3 (assay ID Rn00563784_m1), OX-42 (Rn00709342_m1), GFAP (Rn01460868_m1), IL-6 (Rn00561420_m1), Iba1 (Rn00574125_g1), BDNF exon IX (Rn02531967_s1) and NR2B (Rn00680474_m1) subunit of NMDA receptors. Semi-quantitative determinations were made with reference to the reporter gene encoding glyceraldehyde 3-phosphate dehydrogenase (GaPDH; Rn99999916_s1). The polymerase activation step at $95^{\circ} \mathrm{C}$ for $15 \mathrm{~min}$ was followed by 40 cycles of $15 \mathrm{sec}$ at $95^{\circ} \mathrm{C}$ and $60 \mathrm{sec}$ at $60^{\circ} \mathrm{C}$. Data are presented as relative mRNA units compared with control values (see Latrémolière et al., 2008).

\subsection{Statistical analyses}

All values are expressed as mean \pm S.E.M. Areas under the time-course curves (AUC) were calculated using the trapezoidal rule. Statistical significance of the pressure threshold data was analyzed by 1-way ANOVA with repeated measures (effect of BDNF over time) followed by a Fisher's Protected Least Significant Difference (PLSD) test or a 2-way ANOVA (with factor treatment and repeated measures over time) followed by Bonferroni test. For RTqPCR data, the $2^{-\Delta \Delta C t}$ method (Schmittgen and Livak, 2008) was used to analyze the relative changes in specific mRNA levels. The Student's $t$ test was used to compare 
immunohistochemical and RT-qPCR data in treated versus control group when only 2 groups were analysed. A 1-way ANOVA followed by a Newman Keuls test was used when comparison was made between 3 or more groups. In all cases, significance level was set at $P$ $<0.05$.

\section{Results}

\subsection{Time course development of mechanical hyperalgesia and allodynia in CCI-SN} and BDNF i.t. rats.

CCl-SN induced a progressively developing mechanical hyperalgesia at the ipsilateral hindpaw that reached its maximal intensity two weeks after surgery (Fig. 1 A). BDNF i.t. also induced mechanical hyperalgesia, but more rapidly than $\mathrm{CCI}-\mathrm{SN}$, since the maximal decrease in pressure threshold values determined with the Randall-Selitto test was reached as soon as one week post injection (Fig. 1B). As shown in figure 2, the intensity of mechanical hyperalgesia as assessed from maximal decreases in pressure threshold values to trigger hindpaw withdrawal $(-33.9 \%, \mathrm{P}<0.001)$ and vocalization $(-36.9 \%, \mathrm{P}<0.01)$ in BDNF i.t. versus saline i.t. rats was similar to that found in $\mathrm{CCI}-\mathrm{SN}$ versus sham-operated rats $(-33.4 \%, \mathrm{P}<0.05$, and $-35.8 \%, \mathrm{P}<0.001$, respectively). Furthermore, like that occurring after $\mathrm{CCl}-\mathrm{SN}$, mechanical hyperalgesia evoked by i.t. BDNF was a long lasting response which persisted for at least one month post-injection (Fig. 1B).

Von Frey filaments test showed that mechanical allodynia also developed after CCI-SN (Fig. 1C) and BDNF i.t. (Fig. 1D). Indeed, allodynia was as pronounced and lasted for at least four weeks under either condition (Fig. 1C,1D). However, maximal allodynia-like response was reached much earlier in BDNF i.t.- than in CCI-SN-rats (Fig. 1D compared to Fig. 1C).

\subsection{Effects of various drugs on mechanical hyperalgesia in BDNF i.t. versus CCI-SN-} rats

\subsubsection{Effects of antihyperalgesic drugs, pregabalin and ketamine}


Two weeks after CCl-SN or 10 days after i.t. BDNF, acute treatment with pregabalin (30 $\mathrm{mg} / \mathrm{kg}$ i.p.) significantly reduced hyperalgesia as shown by the return of pressure threshold values up to the range observed in naïve healthy rats subjected to the Randall-Selitto test (Fig. 3A,3B). Similar time courses of the drug effect were observed in both models, with complete reversal of hyperalgesia at 2-3 hours post-treatment, followed by its progressive reappearance down to pre-treatment threshold values $24 \mathrm{~h}$ after pregabalin administration (Fig. 3A,3B). Ketamine (50 mg/kg i.p.) also reduced hyperalgesia in both models (Fig. 3C,3D), but its effects were less pronounced and of shorter duration than pregabalin (Fig. 3C,3D).

\subsubsection{Effects of opioid receptor agonists, morphine and tapentadol}

In both CCI-SN- and BDNF i.t.- rats, acute treatment with morphine (3 mg/kg s.c., Fig. 4A,4B) and tapentadol (10 mg/kg i.p., Fig. 4C,4D) also reduced mechanical hyperalgesia as shown by significant increases in pressure threshold values to trigger vocalization in the Randall-Selitto test. Complete reversal of hyperalgesia was observed up to one hour after morphine administration, but this effect vanished rapidly and was no longer significant one hour later (Fig. 4A,4B). As shown in figure 4C,4D, the effect of tapentadol was even more transient since it had completely disappeared 90 min after the drug administration.

\subsubsection{Effects of agomelatine, amitriptyline, duloxetine and clonazepam}

As shown in figure $5 \mathrm{~A}, 5 \mathrm{~B}$, acute administration of the antidepressant agomelatine (45 $\mathrm{mg} / \mathrm{kg}$, i.p.) significantly reduced mechanical hyperalgesia in both $\mathrm{CCl}-\mathrm{SN}$ - and BDNF i.t.- rats. These effects were transient since partial recovery of pretreatment threshold values was already observed 30 (Fig. 5B) or 30-60 min (Fig. 5A) after the drug administration.

In contrast with agomelatine, the tricyclic antidepressant amitriptyline (10 mg/kg i.p.) did not significantly affect pressure threshold values at any time up to four hours posttreatment in both $\mathrm{CCl}-\mathrm{SN}$ - and BDNF i.t.- rats (Fig. 5C,5D). Similarly, neither duloxetine (10 $\mathrm{mg} / \mathrm{kg}$ i.p.), nor clonazepam (0.25 mg/kg i.p.) significantly affected pressure threshold values to trigger vocalization in both $\mathrm{CCl}-\mathrm{SN}$ - and BDNF i.t.- rats (not shown).

\subsection{Effects of TrkB receptor blockade by cyclotraxin B}

\subsubsection{Prevention by cyclotraxin B of BDNF i.t.- induced hyperalgesia}


When administered twice, 15 min before and 15 min after i.t. injection of BDNF, cyclotraxin $\mathrm{B}$, at an effective dose $(20 \mathrm{mg} / \mathrm{kg}$ i.p.) to block BDNF-TrkB receptor in the central nervous system (Cazorla et al., 2010), prevented the hyperalgesic-like effect normally induced by the trophic factor. As shown in figure 6, the BDNF-induced decrease in pressure threshold values to trigger hindpaw withdrawal (Fig. 6A) and vocalization (Fig. 6B) in the Randall-Selitto test did not occur for at least one week after cyclotraxin-B administration. On its own, cyclotraxin B did not significantly affect pressure threshold values in naïve rats (not shown).

\subsubsection{Reversal by cyclotraxin B of CCI-SN- and BDNF i.t.-induced hyperalgesia}

When injected two weeks after surgery in CCI-SN rats, cyclotraxin B (two injections at 20 $\mathrm{mg} / \mathrm{kg}$ i.p., $30 \mathrm{~min}$ apart) reversed partially the nerve lesion-induced decrease in pressure threshold value to trigger vocalization in the Randall-Selitto test. As shown in figure $7 \mathrm{~A}, 7 \mathrm{C}$, this anti-hyperalgesic effect developed progressively in CCI-SN rats, up to a maximum 1-5 days after cyclotraxin B, which corresponded to half-recovery of healthy control mechanical sensitivity ( $C$ on abscissa). Thereafter, the effect of cyclotraxin B decreased progressively and was no longer significant on day 10 post-injection (Fig. 7A).

Similarly, cyclotraxin B increased the pressure threshold value to trigger vocalization in rats which had developed hyperalgesia 10 days after BDNF i.t. (Fig. 7B,7D). At its maximum, on days 1-5 post-treatment, cyclotraxin B effect corresponded to half-reversal of BDNF i.t.induced hyperalgesia. Thereafter, this effect progressively vanished and hyperalgesia returned to pretreatment level on day 8 post-injection (Fig. 7B).

\subsection{Neuroinflammation/glial activation markers in the spinal cord and dorsal root ganglia of $\mathrm{CCl}-\mathrm{SN}$ - versus BDNF i.t.- rats}

In CCI-SN rats, significant upregulation of transcripts encoding the neuronal injury marker ATF3 and the microglia activation markers $0 X-42$ and lba1 was observed in both the ipsilateral dorsal quadrant of the lumbar enlargement of the spinal cord $(x 8.57, P<0.01 ; x$ 2.56, $\mathrm{P}<0.001 ; \mathrm{x} 1.47, \mathrm{P}<0.01$, respectively) and ipsilateral L4-L6 DRG (x 16.33, $\mathrm{P}<0.001 ; \mathrm{x}$ 1.76, $\mathrm{P}<0.05 ; x 1.62, \mathrm{P}<0.05$, respectively) two weeks after surgery (Fig. 8). In contrast, one day (not shown) as well as 10 days (Fig. 8) post-injection, when hyperalgesia and allodynia 
had reached their maximal intensities (see Fig. 1B,1D), no changes in spinal cord and DRG levels of mRNAs encoding ATF3, OX-42 and Iba1 were detected in BDNF i.t. rats.

Data in figure 8 also show that $\mathrm{CCl}-\mathrm{SN}$ induced significant upregulation of mRNAs encoding IL-6, BDNF and the NR2B subunit of NMDA receptors in both the ipsilateral dorsal quadrant of the lumbar enlargement of the spinal cord $(x 3.68, \mathrm{P}<0.001 ; x 1.62, \mathrm{P}<0.05 ; \mathrm{x} 1.44, \mathrm{P}<$ 0.05, respectively) and L4-L6 DRG (x 15.43, $\mathrm{P}<0.001 ; \mathrm{x} 1.66, \mathrm{P}<0.05 ; \mathrm{x} 1.67, \mathrm{P}<0.05$, respectively) (Fig. 8). BDNF mRNA upregulation was also observed in the dorsal half of the lumbar enlargement $(x$ 1.42, $P<0.01)$, but not in L4-L6 DRG, of rats with hyperalgesia/allodynia on day 10 post BDNF i.t. (Fig. 8). In contrast, neither IL-6 mRNA nor NR2B mRNA at spinal and DRG levels were significantly changed in BDNF i.t. rats (Fig. 8), and GFAP mRNA remained unaffected by CCI-SN or BDNF i.t. under our experimental conditions (Fig.8, and data not shown).

\subsection{Immunohistochemical labeling of P-p38 at spinal level in CCI-SN- versus BDNF i.t.- rats}

At L4-L6 level of the lumbar enlargement of the spinal cord, a significant increase in the density of P-p38 immunoreactive cells was observed within both superficial (I-II) and deep (III-V) laminae of the dorsal horn ipsilateral to the surgery in CCI-SN-compared to shamoperated-rats (Fig. 9A). A significant increase in P-p38 immunolabeling was also observed within the contralateral dorsal horn, but of lower amplitude (CCI-SN vs sham, laminae I-II: + $26.7 \pm 8.7 \%, \mathrm{P}<0.01$; laminae III-V: $+64.7 \pm 10.8 \%, \mathrm{P}<0.01$, not shown) than that observed in the ipsilateral dorsal horn (CCI-SN vs sham, laminae I-II: + $64.0 \pm 8.8 \%, \mathrm{P}<0.001$; laminae III-V: $+145.2 \pm 11.6 \%, \mathrm{P}<0.001$ ) (Fig. 9A). In contrast, no significant change in P-p38 immunostaining was detected within the dorsal horn of the lumbar enlargement in BDNF i.t. rats (Fig. 9B). However, stroking stimulation of the right hindpaw under conditions that did not affect P-p38 immunolabeling in control (saline i.t.) rats did produce significant increases in the density of P-p38 immunoreactive cells within both the superficial laminae I-II and deep laminae III-V of the ipsilateral dorsal horn in BDNF i.t. rats (Fig. 9B).

\section{Discussion}


Our data showed that spinal administration of BDNF triggered sustained hyperalgesia- and allodynia-like behaviors in naïve healthy rats to the same extent as CCI-SN, further supporting the idea that this neurotrophin plays a cardinal role in physiopathological mechanisms underlying neuropathic pain (Pezet and McMahon, 2006). In both BDNF i.t.- and $\mathrm{CCl}$-SN-rats, activation of BDNF TrkB receptor appeared to play a key role in the maintenance of neuropathic-like pain because systemic administration of cyclotraxin $B$, at a dose $(2 \times 20$ $\mathrm{mg} / \mathrm{kg}$ i.p.) blocking TrkB in the central nervous system (Cazorla et al., 2010), significantly reduced hyperalgesia. Interestingly, the antihyperalgesic effect of cyclotraxin B lasted for at least 5 days after its administration, showing the powerful efficacy of blocking BDNF/TrkB signaling pathway to relieve neuropathic-like pain. Such a long lasting effect of cyclotraxin B, which confirmed previous data obtained in rats with infraorbital nerve ligation or injected intracisternally with BDNF (Constandil et al., 2012), might be explained by the capacity of TrkB blockade to prevent synaptic sensitization underlying hyperalgesic processes. Indeed, long term potentiation (LTP), that can be induced by BDNF at spinal level (Zhou et al., 2010), plays a key role in synaptic sensitization and the blockade by cyclotraxin B of BDNF action might suppress the occurrence of LTP at spinal level. To date, however, the capacity of cyclotraxin B to prevent BDNF-induced LTP has been demonstrated in the hippocampus only (Cazorla et al., 2010).

Interestingly, TrkB receptor blockade by cyclotraxin B, at a dose $(2 \times 20 \mathrm{mg} / \mathrm{kg}$ i.p. $)$ preventing completely the development of BDNF i.t.-induced hyperalgesia (Fig. 6), only partially reversed hyperalgesia once this neuropathic pain-related symptom had fully developed, 10 days after BDNF i.t. or two weeks after CCI-SN (Fig. 7). This might suggest that not only TrkB but also the low affinity BDNF receptor p75 could be implicated in the maintenance of BDNF-i.t.- as well as $\mathrm{CCl}-\mathrm{SN}$-induced hyperalgesia, as proposed by Obata et al. (2006). Further investigations will have to assess this point as well as exploring whether cyclotraxin B would affect not only the maintenance but also the development of CCl-SNinduced neuropathic pain.

Such close similarities in TrkB-dependent hyperalgesia-like behavior in BDNF i.t.- and CCI-SNrats led us to investigate respective underlying physiopathological mechanisms. In the case of $\mathrm{CCl}-\mathrm{SN}$, neural injury resulted in upregulation of transcripts encoding ATF3, microglial activation markers $\mathrm{OX}-42$ and Iba1 as well as downstream products including the 
proinflammatory cytokine IL-6, BDNF and the NR2B subunit of NMDA receptors in both spinal and DRG tissues, in line with previous reports (Latrémolière et al., 2008; Zhuo et al., 2011). That microglial activation and downstream signaling cascades play a key role in the induction of neuropathic pain after nerve lesion is notably supported by data showing that the administration of minocycline, a microglial inhibitor, attenuates neuropathic pain development in nerve lesioned rats (Latrémolière et al., 2008). In contrast, no sign of neural injury, as shown by unchanged expression of ATF3, and no evidence of microglia activation, neither in DRG nor in spinal cord tissues after i.t. BDNF indicating that the latter treatment did not really mimic the complex neuropathic condition induced by $\mathrm{CCl}-\mathrm{SN}$. Accordingly, immunolabeling of the microglial activation marker, P-p38, was enhanced in CCI-SN rats but not in BDNF i.t. rats (Fig. 9). In contrast, Zhou et al. (2010) previously reported that a transient microglial activation could be induced by i.t. administration of BDNF, suggesting that our investigations only in unstimulated BDNF i.t. rats were not enough to reach a clearcut conclusion. This led us to submit BDNF i.t. rats to a sustained unilateral mechanical, non nociceptive, stimulation of the hindlimb, which was previously shown to allow the detection of nociceptive pathway sensitization (Kayser et al., 2010). A clear-cut increase in the density of P-p38 immunoreactive cells was thus observed within the dorsal horn of the lumbar cord in BDNF i.t. rats, indicating that microglial activation might also occur in these animals.

Of all the transcripts investigated in our studies, only the one encoding BDNF (exon IX) was found to be upregulated within the dorsal horn of BDNF i.t. rats, in line with previous data showing that this neurotrophic factor can promote its own synthesis (Cheng et al., 2011; Zheng et al., 2012). Such autocrine action of BDNF very probably explains why a single i.t. administration of this neurotrophin produced a long-lasting TrkB-mediated neuropathic pain-like effect. Whether similar BDNF autocrine effect also underlay the maintenance of $\mathrm{CCl}-\mathrm{SN}$-induced neuropathic pain will have to be assessed by comparing the effects of cyclotraxin B on the expression of genes downstream of TrkB activation in both CCI-SN and BDNF-it rats.

In further support to the existence of close homology between the effects of BDNF i.t. and $\mathrm{CCl}-\mathrm{SN}$, drugs used to treat neuropathic pain in humans such as pregabalin, tapentadol and morphine (Finnerup et al., 2015) were found to be equally effective to reduce hyperalgesia in both models. In contrast, amitriptyline, duloxetine and clonazepam were equally 
ineffective under the acute treatment conditions used in our studies, in line with convergent data showing that these drugs, especially antidepressants, have to be administered chronically to exert significant anti-hyperalgesic effects (Benbouzid et al., 2008). However, this was not the case with agomelatine since acute administration of this antidepressant significantly reduced hyperalgesia in both models. Agomelatine is an agonist at melatonergic MT1 and MT2 receptors and an antagonist at 5- $\mathrm{HT}_{2 \mathrm{~B}}$ and $5-\mathrm{HT}_{2 \mathrm{C}}$ receptors (de Bodinat et al., 2010), which are all relevant targets for neuropathic pain alleviation (Ambriz-Tututi et al., 2009; Viguier et al., 2013). Accordingly, concomitant actions at these receptors might account for its unique antihyperalgesic efficacy when compared to other antidepressants under acute treatment conditions. Interestingly, agomelatine was found to enhance BDNF expression in the rat hippocampus (Soumier et al., 2009), and it would therefore be of interest to assess its effect on BDNF expression and TrkB activity at the spinal level.

Interestingly, the NMDA receptor antagonist ketamine was also found to inhibit both $\mathrm{CCl}-\mathrm{SN}$ and BDNF i.t.-induced hyperalgesia, as expected from convergent data showing that BDNFinduced synaptic sensitization is mediated through facilitation of NMDA receptor-dependent glutamatergic nociceptive pathways (Geng et al., 2010; Chen et al., 2014). As mRNA encoding the NR2B subunit of NMDA receptors was not upregulated 10 days after BDNF i.t. injection, when hyperalgesia had fully developed, it can be inferred that BDNF did not induce NR2B transcription but most probably promoted its activation via phosphorylation, as previously reported in cortical and hippocampal neurons (Lin et al., 1998).

In addition to promoting NMDA receptor-mediated neurotransmission, BDNF is known to downregulate the expression and activity of the $\mathrm{KCC} 2 \mathrm{~K}^{+} / \mathrm{Cl}^{-}$co-transporter, which reduces the hyperpolarizing/inhibitory properties of GABA (Coull et al., 2005). Whether this mechanism also contributes to BDNF i.t.- induced hyperalgesia/allodynia is an interesting possibility to be addressed in future investigations.

\section{Role of the funding source}

This research has been supported by grants from INSERM, University Pierre and Marie Curie (UPMC) and ANR (Contract 11 BSV4 017 04, "TrkBDNFarmod"). Saïd M'Dahoma was 
supported by fellowships from the University Paris Descartes (UPD, Paris 5) during performance of this work. INSERM, UPMC, ANR and UPD had no further role in study design; in the collection, analysis and interpretation of data; in the writing of the report; and in the decision to submit the paper for publication.

\section{Contributors}

Said M'Dahoma, Michel Hamon and Sylvie Bourgoin designed the study, analysed the data and wrote the first draft of the paper. Sylvie Bourgoin performed the surgical procedure and Said M'Dahoma, Claire Tromilin, Tiffany Jeanson and Florent Viguier carried out the behavioral pharmacology experiments. Saïd M'Dahoma, Sandrine Barthelemy, Benoit Michot and Sophie Pezet conduced the RT-qPCR determinations and quantitative immunohistochemical labeling. All authors contributed to the study and have approved the final manuscript.

\section{Conflict of interest}

All authors declare that they have no conflicts of interest.

\section{Acknowledgements}

We are grateful to pharmaceutical companies (Grünenthal, Servier) for generous gifts of drugs. We warmly thank Tevrasamy Marday for his excellent care of rats in our laboratory facility.

\section{References}

Ambriz-Tututi, M., Rocha-Gonzàlez, H.I., Cruz, S.L., Granados-Soto, V., 2009. Melatonin : a hormone that modulates pain. Life Sci. 84, 489-498.

Autry, A.E., Monteggia, L.M., 2012. Brain-derived neurotrophic factor and neuropsychiatric disorders. Pharmacol. Rev. 64, 238-258. 
Benbouzid, M., Choucair-Jaafar, N., Yalcin, I., Waltisperger, E., Muller, A., Freund-Mercier, M.J., Barrot, M., 2008. Chronic, but not acute, tricyclic antidepressant treatment alleviates neuropathic allodynia after sciatic nerve cuffing in mice. Eur. J. Pain 12, 10081017.

Bennett, G.J., Xie, Y.K.A., 1988. Peripheral mononeuropathy in rat that produces disorders of pain sensation like those seen in man. Pain 33, 87-107.

Berton, O., McClung, C., DiLeone, R., Krishnan, V., Renthal, W., Russo, S.J., Graham, D., Tsankova, N.M., Bolanos, C.A., Rios, M., Monteggia, L.M., Self, D.W., Nestler, E.J., 2006. Essential role of BDNF in the mesolimbic dopamine pathway in social defeat stress. Science 311, 864-868.

Cai, S., Huang, S., Hao, W., 2015. New hypothesis and treatment targets of depression: an integrated view of key findings. Neurosci. Bull. 31, 61-74.

Calabrese, F., Rossetti, A.C., Racagni, G., Gass, P., Riva, M.A., Molteni, R., 2014. Brain-derived neurotrophic factor: a bridge between inflammation and neuroplasticity. Front. Cell. Neurosci. 8 (430), 1-7.

Cazorla, M., Jouvenceau, A., Rose, C., Guilloux, J.P., Pilon, C., Dranovsky, A., Prémont, J., 2010. Cyclotraxin-B, the first highly potent and selective TrkB inhibitor, has anxiolytic properties in mice. PLoS One 5(3), e9777.

Cejas, P.J., Martinez, M., Karmally, S., McKillop, M., McKillop, J., Plunkett, J.A., Oudega, M., Eaton, M.J., 2000. Lumbar transplant of neurons genetically modified to secrete brainderived neurotrophic factor attenuates allodynia and hyperalgesia after sciatic nerve constriction. Pain 86, 195-210.

Chaplan, S.R., Bach, F.W., Pogrel, J.W., Chung, J.M., Yaksh, T.L., 1994. Quantitative assessment of tactile allodynia in the rat paw. J. Neurosci. Methods 53, 55-63.

Chen, W., Walwyn, W., Ennes, H.S., Kim, H., McRoberts, J.A., Marvizon, J.C.G., 2014. BDNF released during neuropathic pain potentiates NMDA receptors in primary afferent terminals. Eur. J. Neurosci. 39, 1439-1454. 
Cheng, P.-L., Song, A.-H., Wong, Y.-H., Wang, S., Zhang, X., Poo, M.-M., 2011. Self-amplifying autocrine actions of BDNF in axon development. Proc. Natl. Acad. Sci. USA 108,1843018435.

Chopra, K., Arora, V., 2014. An intricate relationship between pain and depression: clinical correlates, coactivation factors and therapeutic targets. Expert Opin. Ther. Targets 18, 159-176.

Constandil, L., Aguilera, R., Goich, M., Hernández, A., Alvarez, P., Infante, C., Pelissier, T., 2011. Involvement of spinal cord BDNF in the generation and maintenance of chronic neuropathic pain in rats. Brain Res. Bull. 86, 454-459.

Constandil, L., Goich, M., Hernández, A., Bourgeais, L., Cazorla, M., Hamon, M., Villanueva, L., Pelissier, T., 2012. Cyclotraxin-B, a new TrkB antagonist, and glial blockade by propentofylline, equally prevent and reverse cold allodynia induced by BDNF or partial infraorbital nerve constriction in mice. J. Pain 13, 579-589.

Coull, J.A., Beggs, S., Boudreau, D., Boivin, D., Tsuda, M., Inoue, K., Gravel, C., Salter, M.W., De Koninck, Y., 2005. BDNF from microglia causes the shift in neuronal anion gradient underlying neuropathic pain. Nature 438, 1017-1021.

de Bodinat, C., Guardiola-Lemaitre, B., Mocaër, E., Renard, P., Munoz, C., Millan, M.J., 2010. Agomelatine, the first melatonergic antidepressant: discovery, characterization and development. Nat. Rev. Drug Discov. 9, 628-642.

Finnerup, N.B., Attal, N., Haroutounian, S., McNicol, E., Baron, R., Dworkin, R.H., Gilron, I., Haanpaa, M., Hansson, P., Jensen, T.S., Kamerman, P.R., Lund, K., Moore, A., Raja, S.N., Rice, A.S.C., Rowbotham, M., Sena, E., Siddall, P., Smith, B.H., Wallace, M., 2015. Pharmacotherapy for neuropathic pain in adults: a systematic review and meta-analysis. Lancet Neurol. 14, 162-173.

Geng, S.J., Liao, F.F., Dang, W.H., Ding, X., Liu, X.D., Cai, J., Han, J.S., Wan, Y., Xing, G.G., 2010. Contribution of the spinal cord BDNF to the development of neuropathic pain by activation of the NR2B-containing NMDA receptors in rats with spinal nerve ligation. Exp. Neurol. 222, 256-266. 
Groth, R., Aanonsen, L., 2002. Spinal brain-derived neurotrophic factor (BDNF) produces hyperalgesia in normal mice while antisense directed against either BDNF or TrkB, prevent inflammation-induced hyperalgesia. Pain 100, 171-181.

Jin, S.X., Zhuang, Z.Y., Woolf, C.J., Ji, R.R., 2003. p38 mitogen-activated protein kinase is activated after a spinal nerve ligation in spinal cord microglia and dorsal root ganglion neurons and contributes to the generation of neuropathic pain. J. Neurosci. 23, 40174022.

Kayser, V., Viguier, F., loannidi, M., Bernard, J.F., Latrémolière, A., Michot, B., Vela, J.M., Buschmann, H., Hamon, M., Bourgoin, S., 2010. Differential anti-neuropathic pain effects of tetrodotoxin in sciatic nerve-versus infraorbital nerve-ligated rats Behavioral, pharmacological and immunohistochemical investigations. Neuropharmacology 58, 474-487.

Latrémolière, A., Mauborgne, A., Masson, J., Bourgoin, S., Kayser, V., Hamon, M., Pohl, M., 2008. Differential implication of proinflammatory cytokine interleukin-6 in the development of cephalic versus extracephalic neuropathic pain in rats. J. Neurosci. 28, 8489-8501.

Lau, W., Dykstra, C., Thevarkunnel, S., Silenieks, L.B., de Lannoy, I.A.M., Lee, D.K.H., Higgins, G.A., 2013. A back translation of pregabalin and carbamazepine against evoked and nonevoked endpoints in the rat spared nerve injury model of neuropathic pain. Neuropharmacology 73, 204-215.

Lever, I.J., Cunningham, J., Grist, J., Yip, P.K., Malcangio, M., 2003. Release of BDNF and GABA in the dorsal horn of neuropathic rats. Eur. J. Neurosci. 18, 1169-1174.

Lin, S.Y., Wu, K., Levine, E.S., Mount, H.T., Suen, P.C., Black, I.B., 1998. BDNF acutely increases tyrosine phosphorylation of the NMDA receptor subunit $2 \mathrm{~B}$ in cortical and hippocampal postsynaptic densities. Brain Res. Mol. Brain Res. 55, 20-27.

Lindholm, J.S.O., Castrén, E., 2014. Mice with altered BDNF signaling as models for mood disorders and antidepressant effects. Front. Behav. Neurosci. 8 (143), 1-10. 
M’Dahoma, S., Bourgoin, S., Kayser, V., Barthélemy, S., Chevarin, C., Chali, F., Orsal, D., Hamon M., 2014. Spinal cord transection-induced allodynia in rats - Behavioral, physiopathological and pharmacological characterization. PLoS One 9(7), e102027.

Mestre, C., Pélissier, T., Fialip, J., Wilcox, G., Eschalier, A., 1994. A method to perform direct transcutaneous intrathecal injection in rats. J. Pharmacol. Toxicol. Methods 32, 197-200.

Michot, B., Bourgoin, S., Kayser, V., Hamon, M., 2013. Effects of tapentadol on mechanical hypersensitivity in rats with ligatures of the infraorbital nerve versus the sciatic nerve. Eur. J. Pain 17, 867-880.

Obata, K., Katsura, H., Sakurai, J., Kobayashi, K., Yamanaka, H., Dai, Y., Fukuoka, T., Noguchi, K., 2006. Suppression of the p75 neurotrophin receptor in uninjured sensory neurons reduces neuropathic pain after nerve injury. J. Neurosci. 26, 11974-11986.

Pezet, S., McMahon, S.B., 2006. Neurotrophins: Mediators and modulators of pain. Annu. Rev. Neurosci. 29, 507-538.

Randall, L.O., Selitto, J.J., 1957. A method for measurement of analgesic activity on inflamed tissue. Arch. Int. Pharmacodyn. Ther. 111, 409-419.

Schmittgen, T.D., Livak, K.J., 2008. Analyzing real-time PCR data by the comparative C(T) method. Nat. Protoc. 3, 1101-1108.

Shirayama, Y., Chen, A.C., Nakagawa, S., Russell, D.S., Duman, R.S., 2002. Brain-derived neurotrophic factor produces antidepressant effects in behavioral models of depression. J. Neurosci. 22, 3251-3261.

Soumier, A., Banasr, M., Lortet, S., Masmejean, F., Bernard, N., Kerkerian-Le Goff, L., Gabriel, C., Millan, M.J., Mocaer, E., Daszuta, A., 2009. Mechanisms contributing to the phasedependent regulation of neurogenesis by the novel antidepressant, agomelatine, in the adult rat hippocampus. Neuropsychopharmacology 34, 2390-2403.

Vanelderen, P., Rouwette, T., Kozicz, T., Heylen, R., Van Zundert, J., Roubos, E.W., Vissers, K., 2013. Effects of chronic administration of amitriptyline, gabapentin and minocycline on 
spinal brain-derived neurotrophic factor expression and neuropathic pain behavior in a rat chronic constriction injury model. Reg. Anesth. Pain Med. 38, 124-130.

Viguier, F., Michot, B., Hamon, M., Bourgoin, S., 2013. Multiple roles of serotonin in pain control mechanisms - Implications of $5-\mathrm{HT}_{7}$ and other $5-\mathrm{HT}$ receptor types. Eur. J. Pharmacol. 716, 8-16.

Vranken, J.H., 2012. Elucidation of pathophysiology and treatment of neuropathic pain. Cent. Nerv. Syst. Agents Med. Chem. 12, 304-314.

Zhao, J., Seereeram, A., Nassar, M.A., Levato, A., Pezet, S., Hathaway, G., Morenilla-Palao, C., Stirling, C., Fitzgerald, M., McMahon, S.B., 2006. Nociceptor-derived brain-derived neurotrophic factor regulates acute and inflammatory but not neuropathic pain. Mol. Cell. Neurosci. 31, 539-548.

Zheng, F., Zhou, X., Moon, C., Wang, H., 2012. Regulation of brain-derived neurotrophic factor expression in neurons. Int. J. Physiol. Pathophysiol. Pharmacol. 4, 188-200.

Zhou, L.J., Yang, T., Wei, X., Liu, Y., Xin, W.J., Chen, Y., Pang, R.P., Zang, Y., Li, Y.Y., Liu, X.G., 2010. Brain-derived neurotrophic factor contributes to spinal long-term potentiation and mechanical hypersensitivity by activation of spinal microglia in rat. Brain Behav. Immun. 25, 322-334.

Zhuo, M., Wu, G., Wu, L.J., 2011. Neuronal and microglial mechanisms of neuropathic pain. Mol. Brain 4, 31.

Zimmermann, M., 1983. Ethical guidelines for investigations of experimental pain in conscious animals. Pain 16, 109-110. 


\section{Legends to figures}

Fig. 1 Time-course development of mechanical hyperalgesia and allodynia in CCl-SN-versus BDNF i.t.- rats. Pressure threshold values to trigger vocalization in the Randall-Selitto test (mechanical hyperalgesia, A, B) or hindpaw withdrawal in the von Frey filaments test (mechanical allodynia, C, D) were determined at various times (abscissa) after sciatic nerve ligation $(A, C)$ or i.t. injection of $\operatorname{BDNF}(B, D)$. Parallel measurements were made in shamoperated rats $(A, C)$ and in i.t. saline-injected rats $(B, D)$. Each point is the mean \pm S.E.M. of 6-7 animals per group. ${ }^{*} \mathrm{P}<0.05,{ }^{*} \mathrm{P}<0.01, * * * \mathrm{P}<0.001$ compared to respective controls, two way ANOVA with repeated measures, Bonferroni test.

Fig. 2 Respective characteristics of maximal hyperalgesia induced by CCI-SN versus BDNF i.t. in rats. Pressure threshold values to trigger hindpaw withdrawal (PWT) and vocalization (VT) in the Randall-Selitto test were determined 15 days after sciatic nerve ligation (A) or 10 days after i.t. injection of BDNF (B). Parallel measurements were made at the same times in shamoperated rats $(A)$ and saline i.t. injected rats (B). Each point is the mean + S.E.M. of 15-18 animals per group. ${ }^{*} \mathrm{P}<0.05,{ }^{*} \mathrm{P}<0.01, * * * \mathrm{P}<0.001$ compared to respective controls, Student's t test.

Fig. 3 Anti-hyperalgesic effects of pregabalin (A, B) and ketamine (C, D) in BDNF i.t. (A, C) and $\mathrm{CCl}-\mathrm{SN}(\mathrm{B}, \mathrm{D})$ rats. Acute administration of pregabalin $(30 \mathrm{mg} / \mathrm{kg}$ i.p.), ketamine $(50 \mathrm{mg} / \mathrm{kg}$ i.p.), or saline was performed (arrow, 0 on abscissa) 15 days post-surgery in $\mathrm{CCI}-\mathrm{SN}$ rats or 10 days after i.t. injection of BDNF (3.0 ng). Pressure threshold values to trigger vocalization in the Randall-Selitto test were determined at various times after treatment (D1 : $24 \mathrm{~h}$ posttreatment). Each point is the mean \pm S.E.M. of 6-8 animals per group. $\mathrm{C}$ on abscissa : Control (naïve) rats (prior to $\mathrm{CCl}-\mathrm{SN}$ surgery or i.t. $\mathrm{BDNF}$ ). ${ }^{*} \mathrm{P}<0.05, * * \mathrm{P}<0.01$ compared to respective values in saline-treated rats, two way ANOVA with repeated measures, Bonferroni test.

Fig. 4 Anti-hyperalgesic effects of morphine (A, B) and tapentadol $(C, D)$ in BDNF i.t. $(A, C)$ and $\mathrm{CCl}-\mathrm{SN}(\mathrm{B}, \mathrm{D})$ rats. The same protocols as those described in the legend to figure 3 were 
used but with morphine ( $3 \mathrm{mg} / \mathrm{kg}$ s.c.) or tapentadol (10 mg/kg i.p.). Each point is the mean \pm S.E.M. of vocalization threshold values in 6-10 animals per group. $* \mathrm{P}<0.05$ compared to respective values in saline-treated rats, two way ANOVA with repeated measures, Bonferroni test.

Fig. 5 Effects of agomelatine (A, B) and amitriptyline (C, D) on hyperalgesia induced by i.t. $\operatorname{BDNF}(A, C)$ or $\mathrm{CCl}-\mathrm{SN}(B, D)$ in rats. Agomelatine $(45 \mathrm{mg} / \mathrm{kg}$ i.p.), amitriptyline $(10 \mathrm{mg} / \mathrm{kg}$ i.p.), or their respective vehicle was injected (arrow, 0 on abscissa) under the same conditions as those described for other drugs in Figs 3-4. Each point is the mean \pm S.E.M. of vocalization threshold values in 6-8 animals per group. $* \mathrm{P}<0.05$ compared to respective values in vehicle (A,B: $1 \%$ HEC; $C, D$ : saline)-treated rats, two way ANOVA with repeated measures, Bonferroni test.

Fig. 6 Prevention by cyclotraxin B of i.t. BDNF-induced hyperalgesia. Cyclotraxin B $(20 \mathrm{mg} / \mathrm{kg}$ i.p.) or saline was injected twice (arrows, 0 on abscissa), 15 minutes before and 15 minutes after i.t. administration of BDNF (3.0 ng). Pressure threshold values to trigger hindpaw withdrawal (A) and vocalization (B) in the Randall-Selitto test were determined at various times (abscissa), up to day 8 post BDNF i.t. Each point is the mean \pm S.E.M. of 5-7 animals per group. $* \mathrm{P}<0.05, * * \mathrm{P}<0.01, * * * \mathrm{P}<0.001$ compared to pressure threshold values just prior to i.t. administration of BDNF ( 0 on abscissa; range values as grey band), one way ANOVA with repeated measures, $\mathrm{PLSD}$ test. $\S \mathrm{P}<0.05$, $\S \S \mathrm{P}<0.01, \S \S \S \mathrm{P}<0.001$ compared to respective values in rats treated with saline + BDNF i.t., two way ANOVA with repeated measures, Bonferroni test.

Fig. 7 Reversal by cyclotraxin B of mechanical hyperalgesia induced by $\mathrm{CCl}-\mathrm{SN}(\mathrm{A}, \mathrm{C})$ or i.t. BDNF (B, D). Cyclotraxin B (20 mg/kg i.p.) or saline was injected twice (0 on abscissa), with a 30 min interval, on day 15 after $\mathrm{CCl}-\mathrm{SN}(\mathrm{A}, \mathrm{C})$ or on day 10 after i.t. administration of BDNF $(B, D)$. Pressure threshold values to trigger vocalization in the Randall-Selitto test were then determined at various times (abscissa), up to day 20 (A) or day 12 (B) after these acute injections. Each point is the mean + S.E.M. of 6 animals per group. C on abscissa : Control (naive) rats (prior to $\mathrm{CCI}-\mathrm{SN}$ surgery or i.t. BDNF). ${ }^{*} \mathrm{P}<0.05$ compared to respective values in 
saline-treated groups, two way ANOVA with repeated measures, Bonferroni test. C,D : Bars are the mean + S.E.M. of AUCS ( $\mathrm{g}$ min) derived from the time-course changes in pressure threshold values in CCI-SN (C from A) or BDNF i.t. ( $D$ from B) rats. ${ }^{* * *} \mathrm{P}<0.001$ compared to respective saline-treated groups, Student's t test.

Fig. 8 Tissue levels of transcripts encoding ATF3, OX-42, Iba1, GFAP, IL-6, BDNF and NR2B in the spinal cord and dorsal root ganglia of CCI-SN- and BDNF i.t.- rats. RT-qPCR determinations were made in dorsal lumbar enlargement and L4-L6 DRG 15 days after CCISN (dorsal quadrant of lumbar enlargement and DRG ipsilateral to $\mathrm{CCI}$ ) and 10 days after BDNF i.t. Parallel measurements were made in respective controls (sham-operated rats and saline i.t. rats). Data are expressed as the ratio of specific mRNA over GaPDH mRNA [R.Q.(A.U.)]. Each bar is the mean + S.E.M. of 7-12 animals per group. ${ }^{*} \mathrm{P}<0.05, * * P<0.01$, *** $\mathrm{P}<0.001$ compared to respective levels in sham-operated $(\mathrm{CCl}-\mathrm{SN})$ or saline-treated (BDNF i.t.) rats, Student's t test.

Fig. 9 Immunohistochemical labeling of the microglial marker P-p38 in the lumbar enlargement of the spinal cord in $\mathrm{CCl}-\mathrm{SN}$ - and BDNF i.t.- rats. A - Left: Typical photomicrographs showing P-p38 immunoreactive cells (black dots) in coronal sections from a sham-operated rat and a CCI-SN rat, 15 days after surgery on the right side; Right: Bar graphs of the mean number (+ S.E.M.) of P-p38 immunoreactive cells counted within the right (ipsilateral to surgery) superficial (I-II) and deep (III-IV-V) laminae - delimited by dotted lines on micrographs - of 26-34 sections from 4 rats in each group. ${ }^{* * *} \mathrm{P}<0.001$, Student's $\mathrm{t}$ test. Scale bar: $250 \mu \mathrm{m}$. B - Left: Typical micrographs showing P-p38 immunoreactive cells (black dots) in coronal sections from a BDNF i.t.- and a saline i.t.- rat 24 hours after nonnoxious mechanical stimulation of right hindpaw (see Experimental procedures); Right: Bar graphs of the mean number (+ S.E.M.) of P-p38 immunoreactive cells counted within the superficial (I-II) and deep (III-IV-V) laminae on the right side of 26-30 sections from 3-4 rats in each group. ${ }^{* *} \mathrm{P}<0.01,{ }^{* * *} \mathrm{P}<0.001$, one way ANOVA, Newman-Keuls test. Scale bar: 250 $\mu \mathrm{m}$ 
Randall \& Selitto test
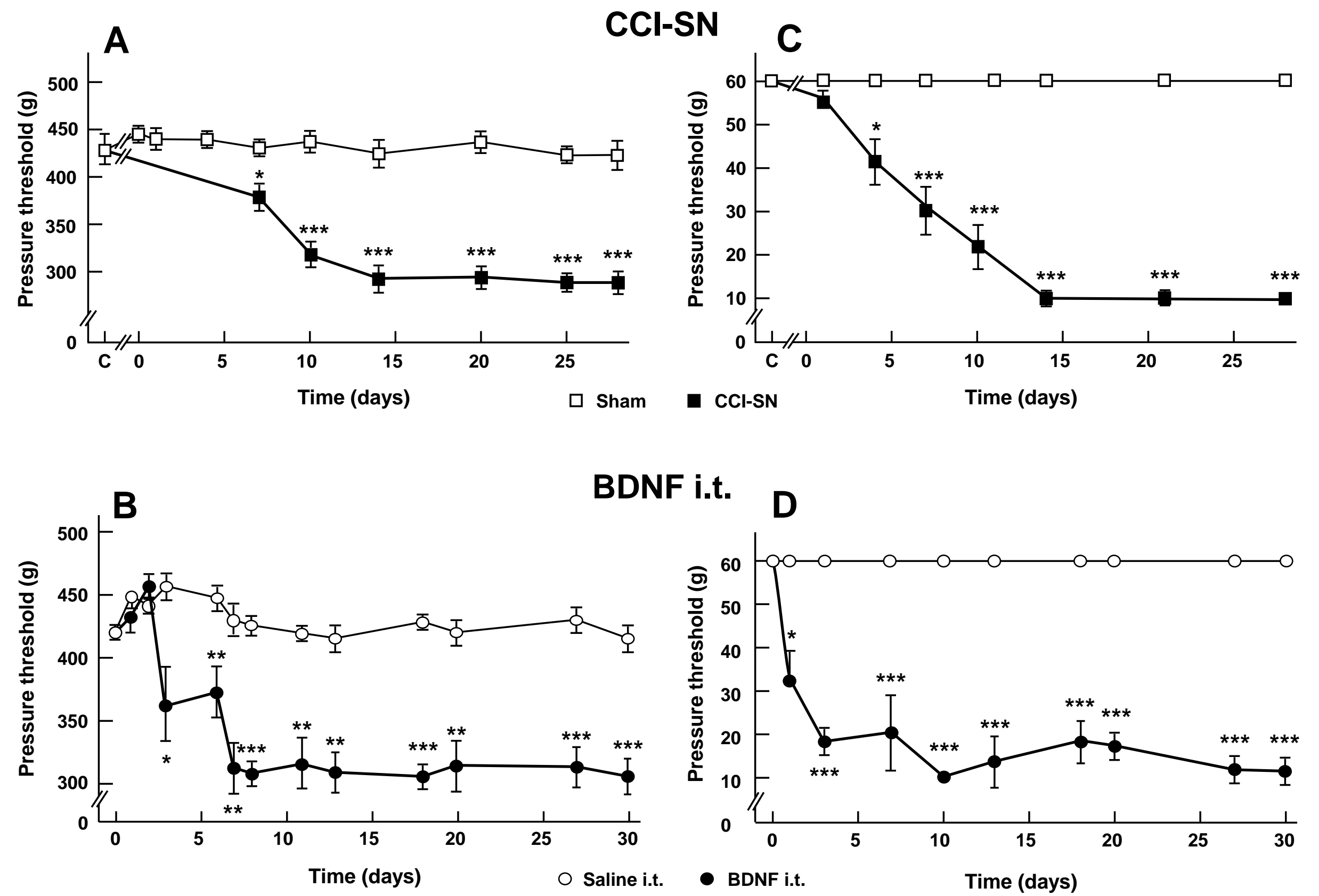

Figure 1 


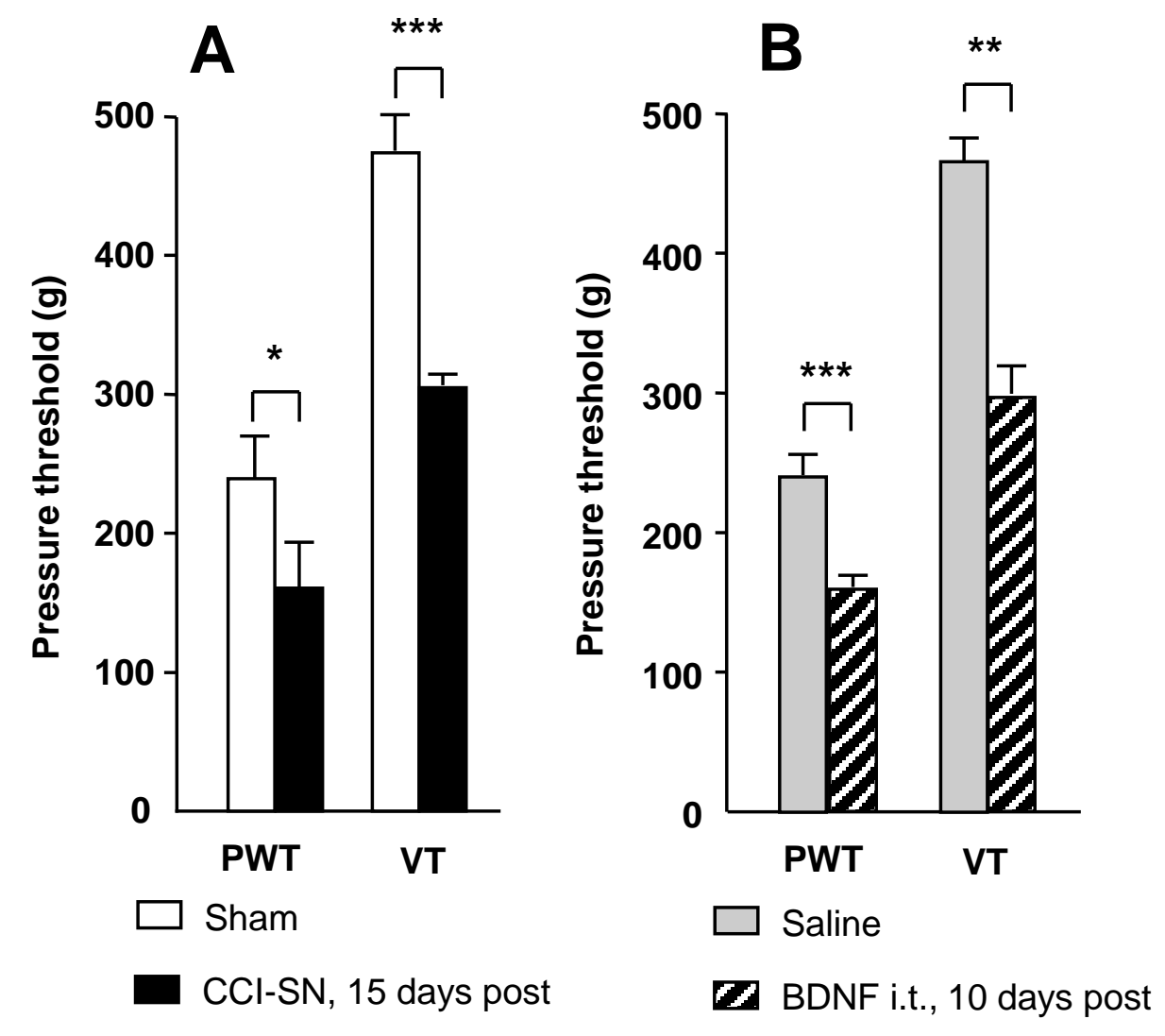

Figure 2 


\section{BDNF i.t.}

\section{CCI-SN}
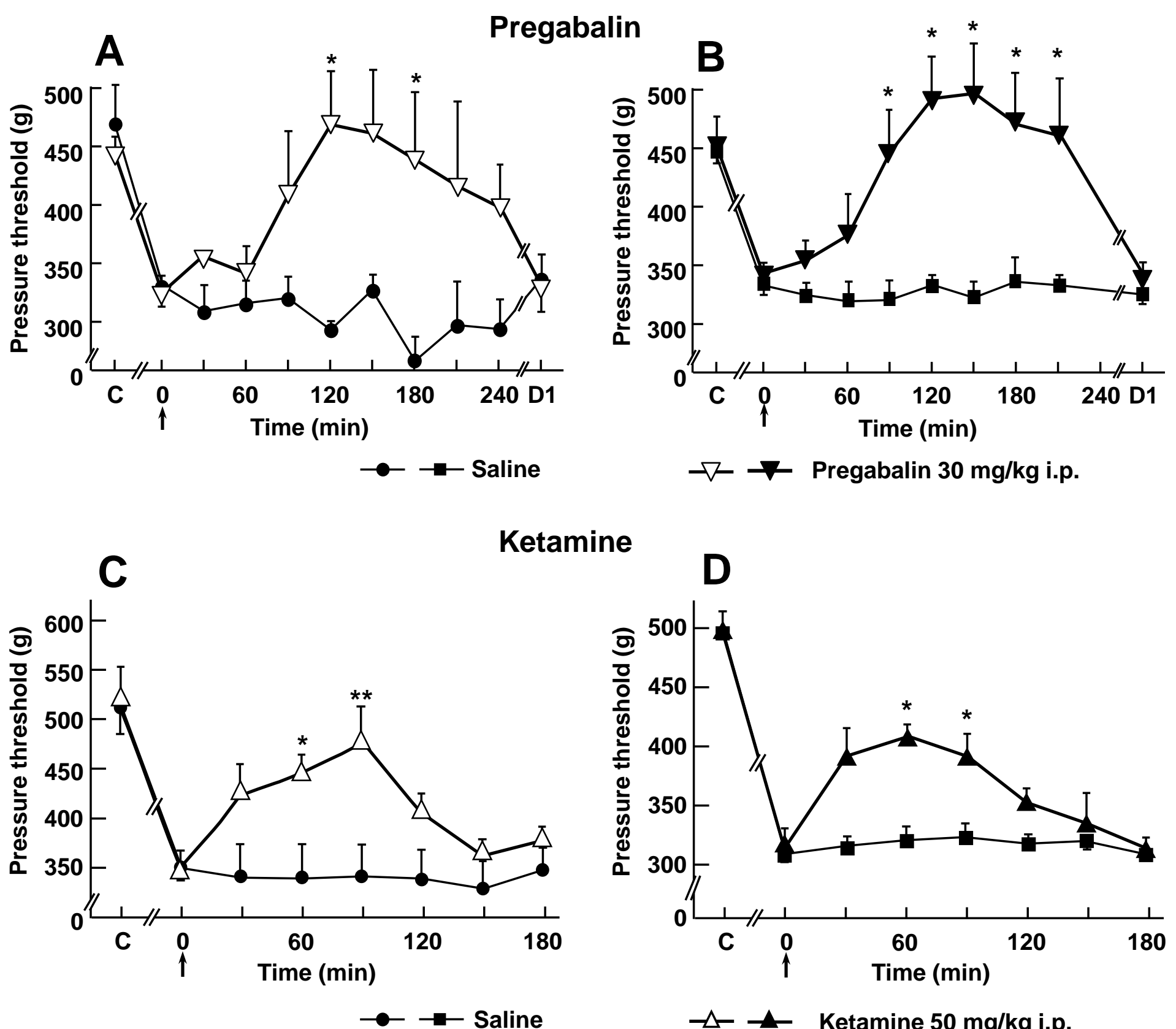

$\rightarrow-\leftarrow$ Saline

$\triangle \neg \quad$ Ketamine 50 mg/kg i.p. 


\section{BDNF i.t.}

\section{CCI-SN}
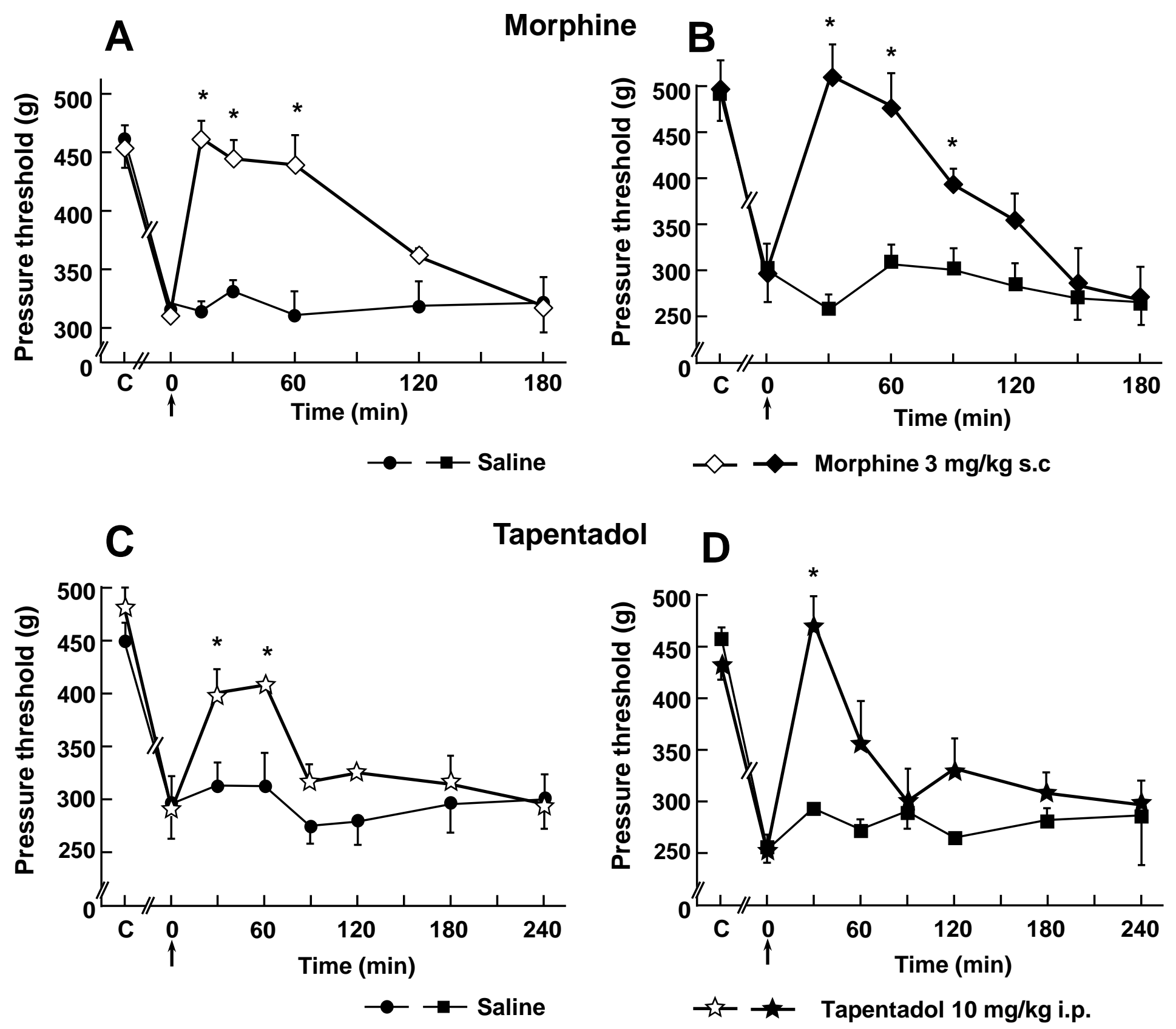
BDNF i.t.

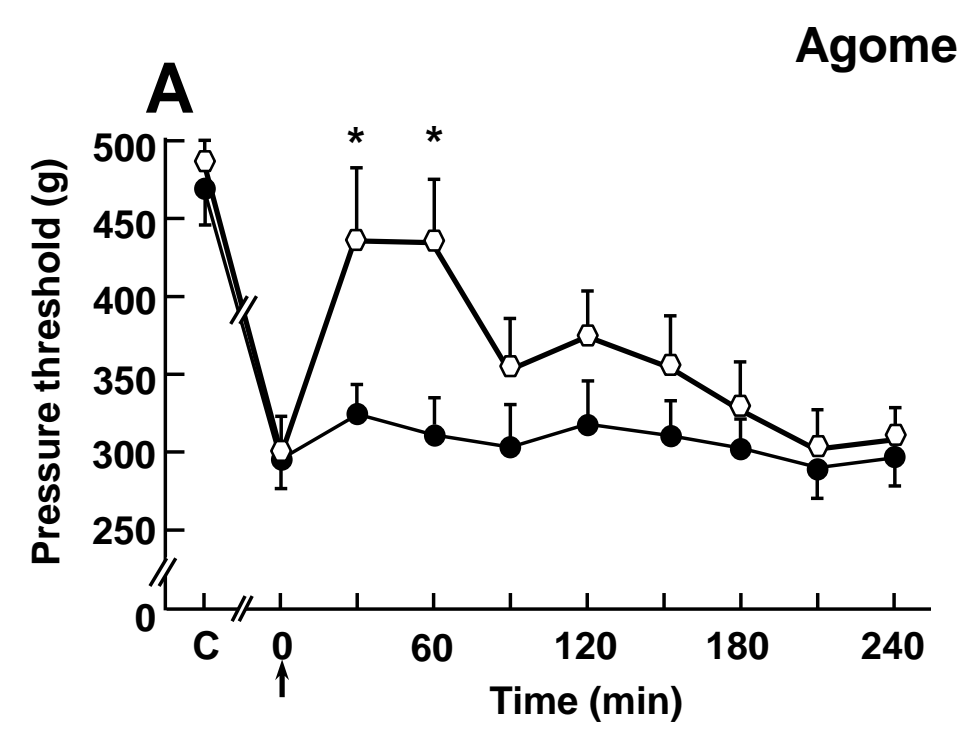

$\rightarrow-$ Vehicle

\section{CCI-SN}

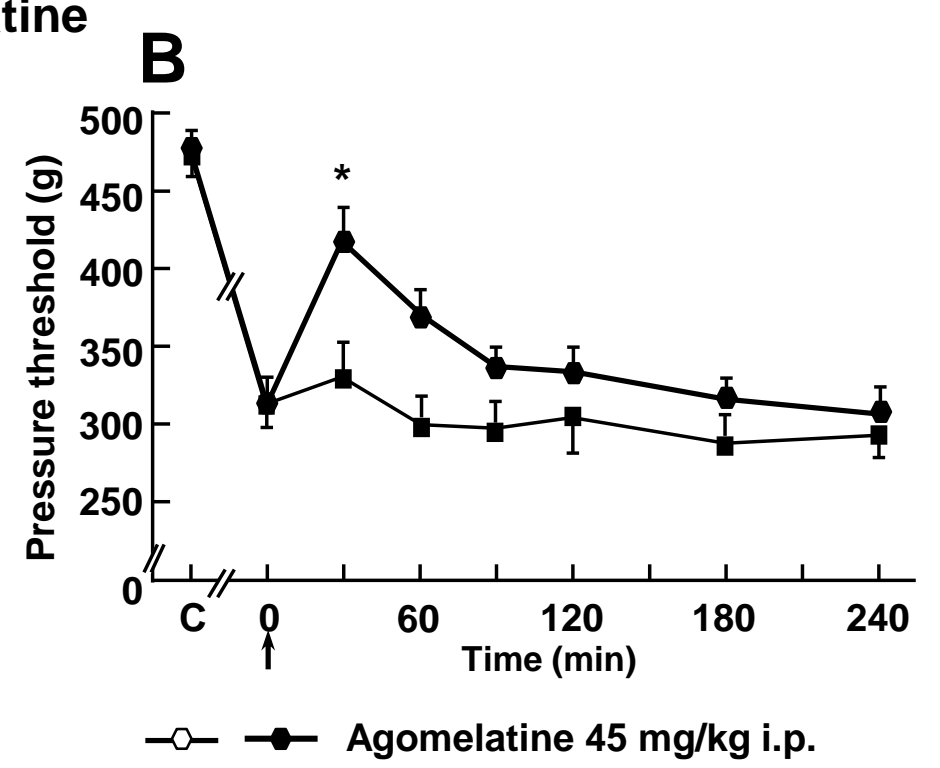

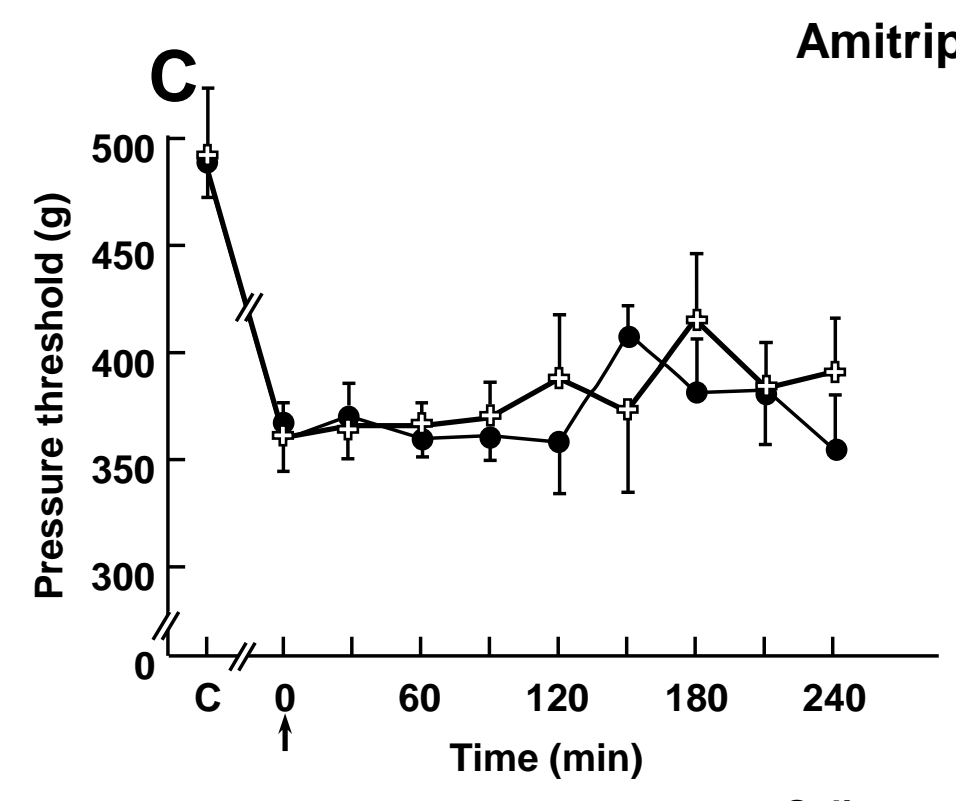

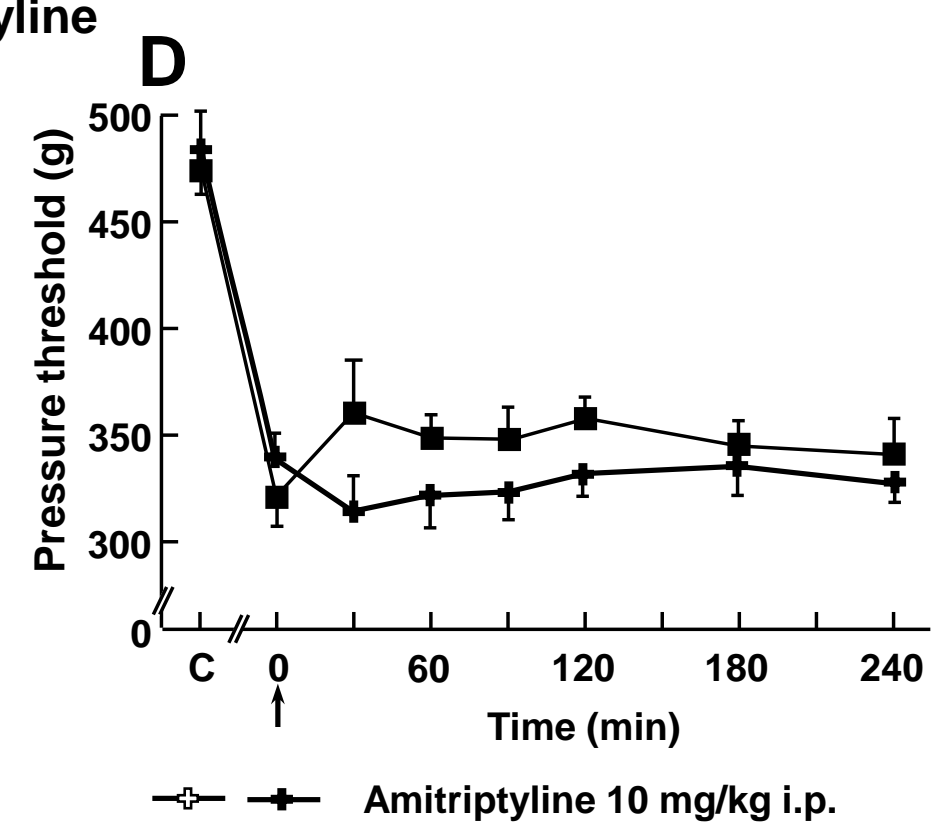



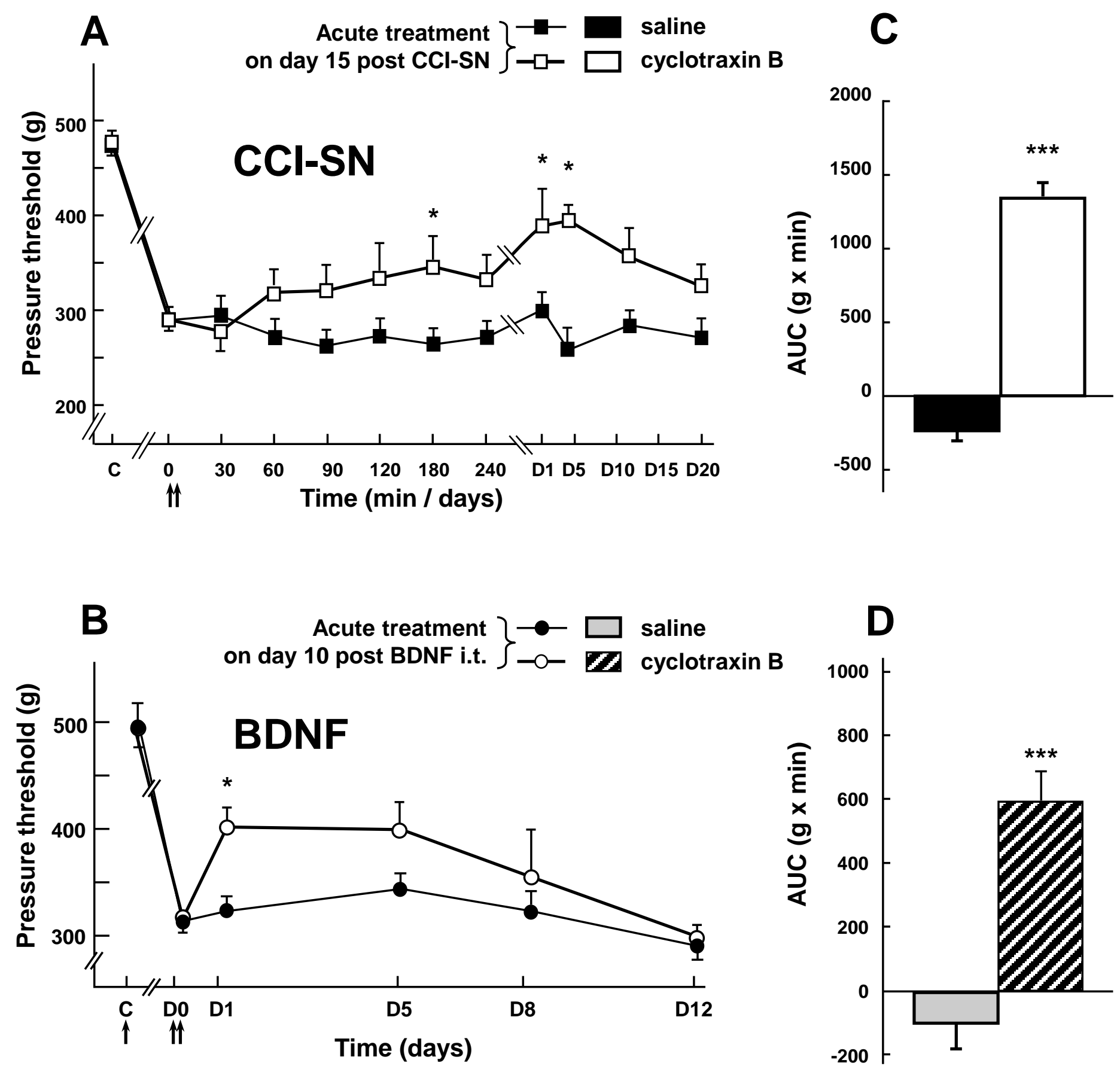


\section{Laminae \\ I-II}

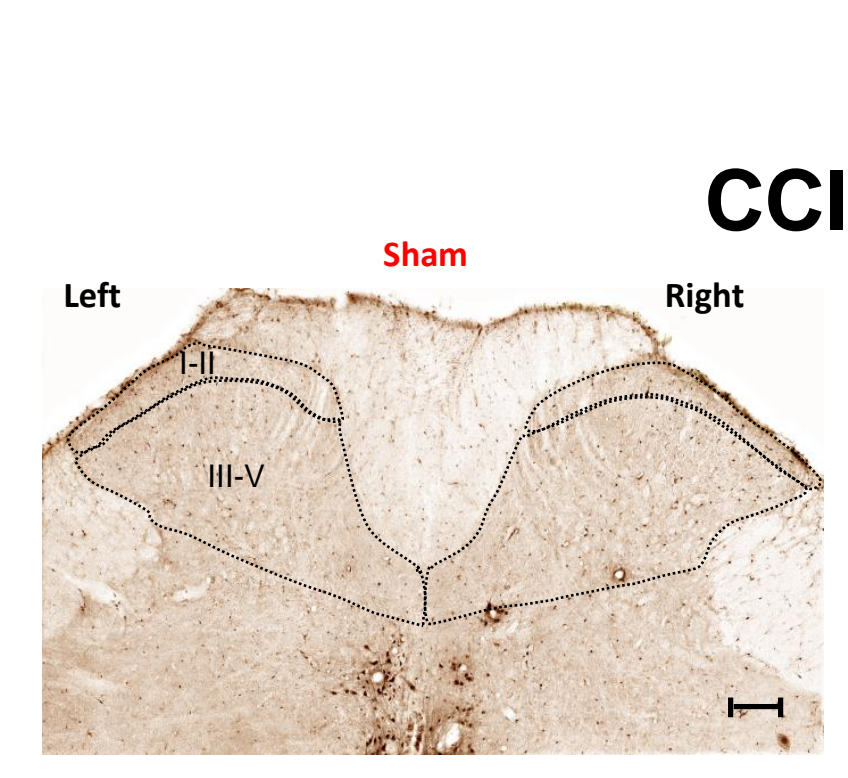

CCI-SN

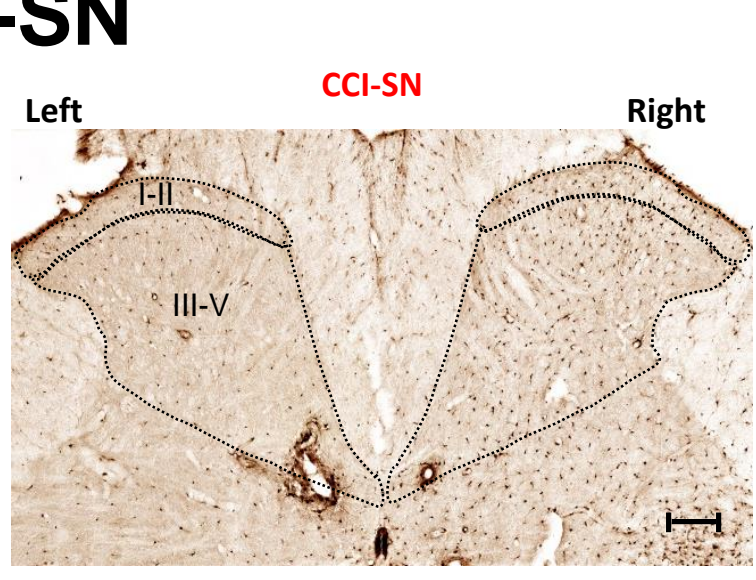

A

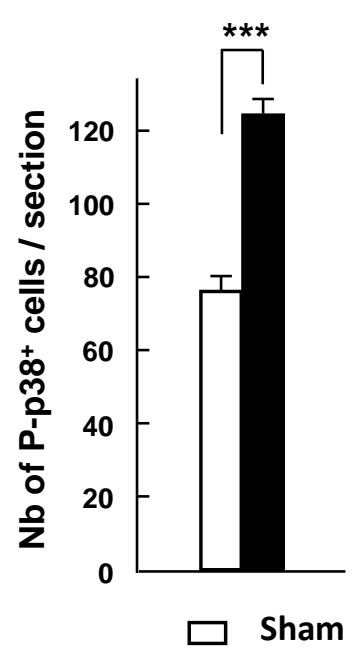

\section{BDNF i.t.}

Saline i.t. stimulated
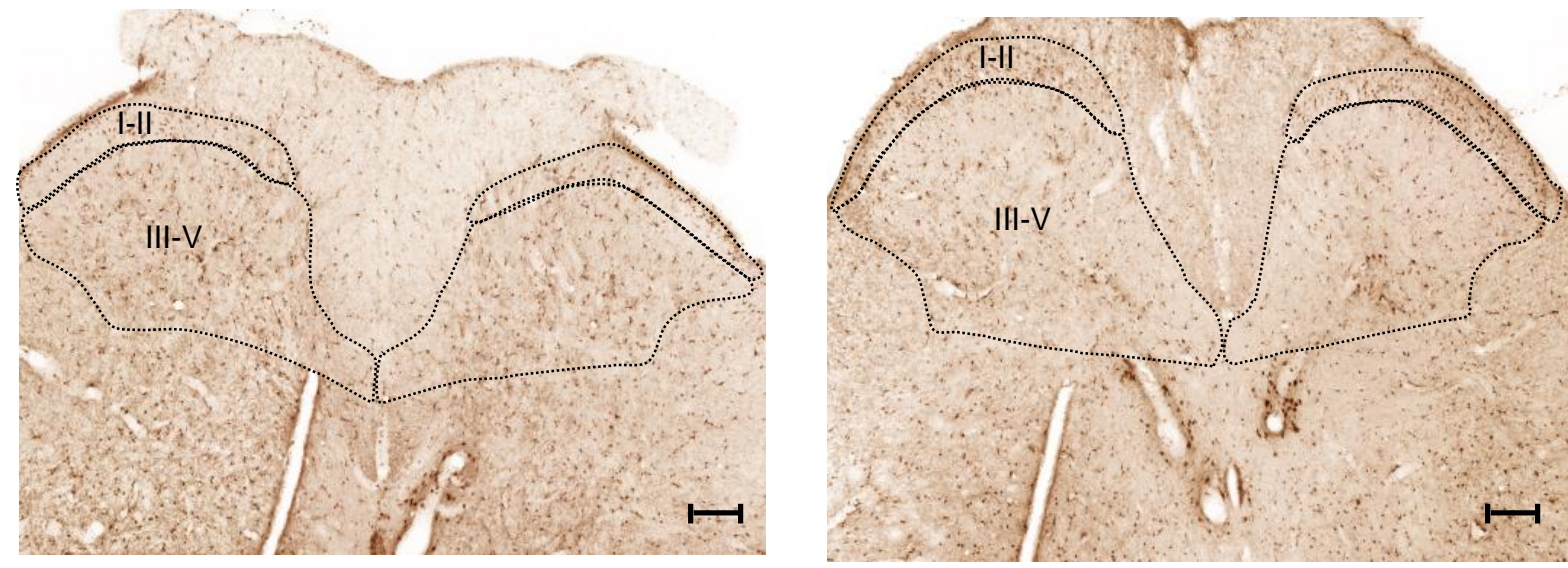

BDNF i.t. stimulated

Figure 9
B

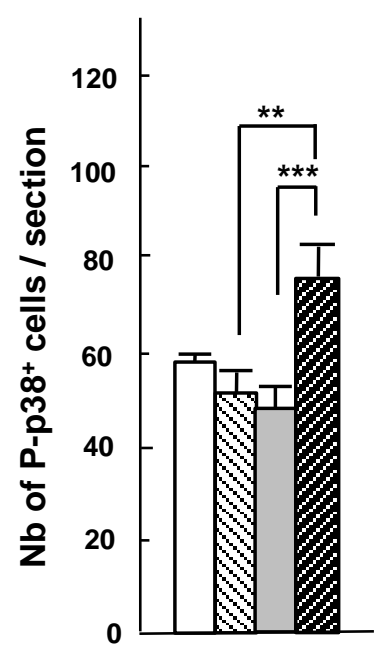

Saline i.t.

Saline i.t., stimulated

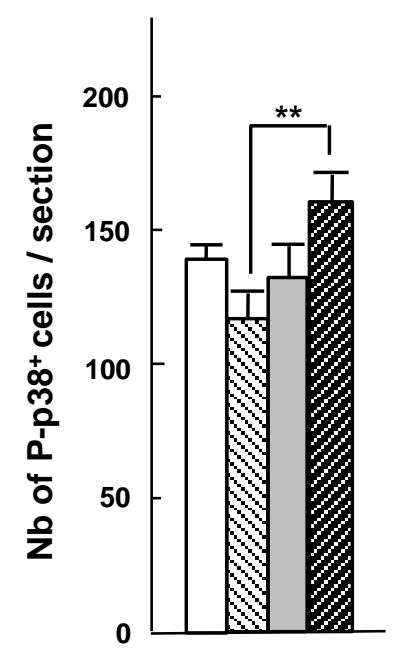

BDNF i.t.

BDNF i.t., stimulated 